International Journal of Engineering \& Technology, $7(3.21)(2018) 270-273$
International Journal of Engineering \& Technology
SPC
Website: $w$ ww.sciencepubco.com/index.php/IJET
Research paper

\title{
Developing a Framework Linking Organizational Creativity Climate, Knowledge Acquisition, and R\&D Performance
}

\author{
Cheng Ling Tan $^{1 *}$, Aizzat Mohd Nasurdin ${ }^{2}$, Sook Fern Yeo ${ }^{3}$ \\ ${ }^{1}$ Graduate School of Business, Universiti Sains Malaysia \\ ${ }^{2}$ School of Management, Universiti Sains Malaysia \\ ${ }^{3}$ Faculty of Business, Multimedia University \\ *Corresponding author E-mail: tanchengling@usm.my
}

\begin{abstract}
R\&D is the key for the knowledge-intensive and high value-added innovations in the firms. To expedite R\&D activities, the Malaysian government increased its $R \& D$ expenditure to motivate $R \& D$ engineers to innovate, to engage actively in the commercialization of patents and the filing of intellectual property. This study aims to identify environmental factors that can intensify the R\&D performance and increase the potential for innovations to be commercialized. Extensive literature review indicated that organizational creative climate influences R\&D performance. Hence, organizational creative climate has been proposed as a significant predictor of R\&D performance. However, inconsistent findings have been reported by various researchers. Therefore, knowledge acquisition capability is added as an intervening variable that can influence the relationship between organizational creative climate and $R \& D$ performance. To the researcher's knowledge, no attempt has been made to integrate the organizational creative climate with knowledge acquisition and R\&D performance. It is hoped that this study will result in a better understanding of the factors that can influence R\&D performance, particularly among medical devices manufacturers.
\end{abstract}

Keywords: $R \& D$ Performance; Knowledge Acquisition; Organizational Creative Climate.

\section{Introduction}

Malaysia is one of Southeast Asia's most dynamic economies because of its impressive economic and social development over the last half-century. In recent years, Malaysia's economy has maintained resilient growth despite facing new competition from its East Asian counterparts (1). For Malaysia to remain competitive, it has to commit to innovation to support a broadbased upgrading towards more knowledge-intensive industries. Research and development (R\&D) plays a crucial role in the innovation process in any industry or technology sector. Technology and innovation are the key driving forces that determine the economic growth and global competitiveness of a nation. The Malaysian government has increased its investment in R\&D with the purpose of motivating $R \& D$ engineers to commercialize their innovative products and services and to increase the filing of intellectual property, as well as scientific publications. Its emphasizes on innovation of substantially improved products and processes in Malaysia has resulted in an increase in the number of R\&D engineers per 10,000 workers from 17.9 in 2006 to 58.2 in 2012. Gross R\&D expenditure in Gross Domestic Product (GDP) also rose from $0.5 \%$ in 2006 to $1.1 \%$ in 2012 (2). Simultaneously, the Gross Expenditure on R\&D (GERD) also increased from 0.64 in 2006 to 1.13 in 2012. Despite the growth of R\&D expenses, Malaysia's performance in innovation has not kept pace with the significant improvements made in other key sectors.

One of the six strategic thrusts in 11th Malaysia Plan is to reengineer economic growth for greater prosperity. While all economic sectors move into more knowledge-intensive and high value- added investments, producing high-value goods and services can generate higher income similar to those in developed countries. Hence, unleash innovation through new or improved processes, advance technologies, and newly generated business models can bring in more revenue, and at the same time produces highly differentiated products and services that satisfy the needs of the ever-changing customers.

Highly knowledge-based industries, such as Medical Devices industry often face challenges in managing the various types of innovation projects, which involves either radical innovations with revolutionary results in technology and product or incremental innovations with minor improvement on the existing technology and product (3). The overall project performance is determined by the ability of the firms to generate new (novel or adopted) ideas and solutions, develop new products and new methods, and produce applicable prototypes or models for the use of the organization. Medical devices are highly demanded and successful R\&D projects are able to develop and produce innovative products and services that can help the organization to face economic complexities and to compete effectively with the competitors. Given the importance of R\&D project performance in enhancing the medical devices manufacturers' growth and performance, this study aims to develop a framework that can link the influencing factors that would enhance the R\&D project performance of medical devices manufacturers. 


\section{Literature Review}

This section started with a literature review on the concept of $\mathrm{R} \& \mathrm{D}$ project performance. It is then followed by the underlying essence of organizational creative climate that sets the foundation as a strong determinant to increase the R\&D performance. After that, the review of many knowledge management literatures is narrowed down to the knowledge acquisition capability in the R\&D project-oriented organizations. This study, finally, develops a link between organizational creative climate, knowledge acquisition capability, and the performance of $\mathrm{R} \& \mathrm{D}$ projects.

\subsection{R\&D Project Performance}

$\mathrm{R} \& \mathrm{D}$ is a major driver for a nation's competitive advantage. Both developed and developing countries are investing heavily in $R \& D$, which leads to an increase in demand for effective evaluation of $R \& D$ project performance (4). $R \& D$ are creative projects conducted systematically to increase the level of knowledge innovations. Complex $R \& D$ projects are characterized by the engagement of complex technical and scientific knowledge, collaborative teamwork, and at the same time, financial restrains and temporal constraints. To manage R\&D effectively, sophisticated methodologies that incorporate rigorous standards, comprehensive guidelines for project documentation, and stringent control over deadlines and milestones. Hence, R\&D projects require a holistic and systematic performance assessment (5), which comprises of two important dimensions, that is, efficiency and technical performance.

Previous studies on R\&D performance focused mainly on the successful implementation of the projects. For instance, Pinto and Slevin (6) explored the effect of both internal and external critical success factors on R\&D project life cycle success. Another determinant of $R \& D$ performance is the incentives given, either in the form of subsidies, grants (particularly research and commercialization grants), or tax incentives (7). Besides, several scholars also included other support systems, such as team leadership and team autonomy (8), cohesion (9), and conflict management (10) as important influencing factors on R\&D performance. Mir and Pinnington (11) highlighted that leadership, staff policy and strategy, partnership and resources, project lifecycle management process, and key performance indicators (KPIs) can influence the success of a project. In a recent study, Joslin and Müller (12) further explored the project management methodology as the key determinant for project success. Alternatively, Aizzat, Tan (13) noted that the creative work climate serves as an important determinant that enables project team members to create new products continuously. This creative climate is found to have critical influence on the success of $R \& D$ performance in organizations (14).

\subsection{Organizational Creative Climate}

In the earlier research, Litwin and Stringer (15) stated that organization climate is the sum of the perceptions of the employees towards the climate of the organization. Later, Ekvall (14) finetuned the definition as a conglomerate of attitudes and feelings, as well as behavior that characterize the lives of organizational members. Veldsman (16) stated that various forces influence the internal environment, which then on employees' behavior, attitudes, and job satisfaction. Dickson, Hartog (17) commented that organizational climate is a multilevel construct that involves distinct perceptions and beliefs regarding the organization's physical and social environment. Base on Arabaci (18), organizational climate was defined as the whole characterizing internal aspects of an organization that affects the behavior of the organizatinal members. However, this climate is perceived differently by each member, which impacts on employee attitudes and behaviors, and affects organizational members' level of organizational commitment and job satisfaction. Simultaneously, it also affects the level of trust and sense of justice perceived by organization members, and results in alienation and exhaustion among organizational members. Open communication is found to an important variable for the creation of an innovative climate, which encourages organizational members to find non-routine alternatives for innovation (19).

Between the 1980s and 1990s, many research began to focus on the organizational climate construct to stimulate innovation and creativity $(20,21)$. As a result, numerous instruments were created among them were the Creative Climate Questionnaire created by Ekvall (14), the Work Environment Inventory formed by Amabile (20), and the Situational Outlook Questionnaire developed by Isaksen (21). In this study, we propose to use the Creative Climate Questionnaire (CCQ), which encompassed ten dimensions, with five items to measure each dimension, that is, a total of 50 items. The ten dimensions include challenge, freedom, trust/openness, dynamism/liveliness, playfulness/humor, debates, conflicts, risk taking, idea time and idea support.

\subsection{Knowledge Acquisition}

Knowledge is the crucial asset if the firm wants to be competitive, and knowledge is found in an organization's human capital (22). Knowledge management is a tool for the firm to reach its goals, through the process of exploring, acquiring and sharing information, thought and experiences among organization members (23). Knowledge served as an input to improve organizational performance, whereby the diversity of ideas and experiences were assembled in an effort to find new and creative approaches to problem-solving, with the aim to elevate firm performance (24). Knowledge acquisition is a sub-process in knowledge process capability that relates to obtaining knowledge for future undertakings. (25) defined it as the activity of capturing expertise from other people or sources of knowledge and utilized this knowledge in the firm to provide help in some specified ways. Information technology and organizational structure, such as leadership and existing organizational culture, is part of the organizational resources that helped in the efficient acquisition of knowledge (26) Individuals can acquire knowledge through observing, experiencing, and interacting with people, either internal or external. Knowledge acquisition is a process of utilizing and acquiring knowledge of the existing knowledge. It needs a concerted effort and a great extent of experience in identifying and capturing the new knowledge. It can be obtained through recognizing and capturing new insights or creating new knowledge from existing knowledge when collaborating with people or business partners.

\section{Conceptual Framework Development}

This study proposes a conceptual framework based on the Knowledge-Based View (27) and its related literature. Knowledge-Based View postulates that knowledge is the primary strategy of a firm's resources to achieve superior performance (27) The Knowledge-Based View explains how organizations can rely on knowledge as the most critical strategy to pursue competitive advantage. When an individual acquires new knowledge, the organization plays a major role in articulating and amplifying that knowledge to achieve innovation. The strategy for knowledge management is linked to knowledge acquisition, dissemination, and utilization (28). The organization could use the available resources in an organization to manage and amplify the newlyacquired knowledge to achieve competitive advantage.

\subsection{Organizational Creative Climate and R\&D Performance}

A growing body of research addresses the fact that organizational creative climate has a positive effect on innovation (29), which 
increases $R \& D$ performance. When a firm has a high level of creative climate, employees may formulate to exchange knowledge for innovative ideas, which will then contribute to higher R\&D performance. Based on Ekvall (14)'s research, the dimensions of dynamism, freedom, risk taking, and debate seemed to be the dimensions that have a critical effect on the innovative climate of an organization. On the other hand, conflict is the single dimension that exerts the strongest negative and restraining effect on R\&D performance. Other than that, the openness of the management in conflict management and the open communication of conflicting technical approaches have a positive effect on innovation (30). Thus, this study proposes that the strong organizational creative climate (trust/openness, dynamism/liveliness, challenge, freedom, playfulness/humor, debates, conflicts, risk taking, idea support, and idea time) will have positive influence on $\mathrm{R} \& \mathrm{D}$ project performance.

In this study, we hypothesise that the challenging climate in the firm will increase the emotional involvement of the $R \& D$ project team and leads to heightened R\&D performance. Besides, the freedom climate encourages the independence of the employees in pursuing initiatives, seeking opportunity to access to information, and seeking alternatives. These proactive behaviors are conducive for innovation, which help to increase R\&D performance. Idea support deals with a level of organizational and peer support given to new ideas and proposals, which will be very useful in contributing to R\&D performance. The trust/openness climate is able to boost emotional safety in work relationships, which eventually will improve R\&D performance. Besides, dynamism/liveliness climate in the organization tend to inspire the team to share knowledge and this, in turn, will contribute to R\&D performance. Sometimes, playfulness/humor climate with spontaneity and laughter that accompany daily works is necessary to reduce the tension existing in the implementation of R\&D projects. The debates climate assures the presence of discussions around viewpoints which is highly needed to improve the $R \& D$ performance. Risk taking climate encourages the tolerance of risks and uncertainty, which results in higher propensity for the employees to experiment. which is an essential element to increase R\&D performance. Idea time refers to the amount of time employees devote to develop new ideas is also a desired factor to improve $R \& D$ performance. Conversely, conflicts climate represents experiences and emotional tensions that may result from the differing viewpoints, tend to restrict and reduce $R \& D$ performance. Based on the discussion above, we speculate that the conflicts climate is negatively influencing the R\&D performance; while the other nine climates positively influence the R\&D performance. In summary, the following hypotheses are proposed:

Hypothesis 1a-1j (H1a-1j): The organizational creative climate, which includes challenge, freedom, idea support, trust/openness, dynamism/liveliness, playfulness/humor, debates, conflicts, risk taking, and idea time influence $\mathrm{R} \& \mathrm{D}$ performance.

\subsection{Knowledge Acquisition as a Mediator}

Past research noted the intervening role of knowledge management on R\&D performance. Tan and Aizzat (31)'s study indicated the mediating role of knowledge management on the relationship between HRM practices and organizational innovation. Rashid Alshekaili (32)'s research found knowledge management as an intervening variable that influences the relationship between human capital and innovation performance. The capability of acquiring knowledge is required by knowledge workers to innovate in order to enhance organizational R\&D performance. Henceforth, knowledge acquisition can be used as a mediator to test its influence on the relationship between organizational creative climate and $R \& D$ performance. Thus, the following hypotheses are formulated:

Hypothesis 2a-2j (H2a-2j): Knowledge acquisition mediates the relationship between organizational creative climate (with the dimensions of challenge, freedom, idea support, trust/openness, dynamism/liveliness, playfulness/humour, debates, conflicts, risk taking and idea time) and R\&D performance.

The conceptual framework is formulated in such a way that organizational creative climate has a direct influence on R\&D performance, while knowledge acquisition acts as a mediator to influence the relationship between organizational creative climate and R\&D performance. The conceptual framework is depicted in Figure 1.

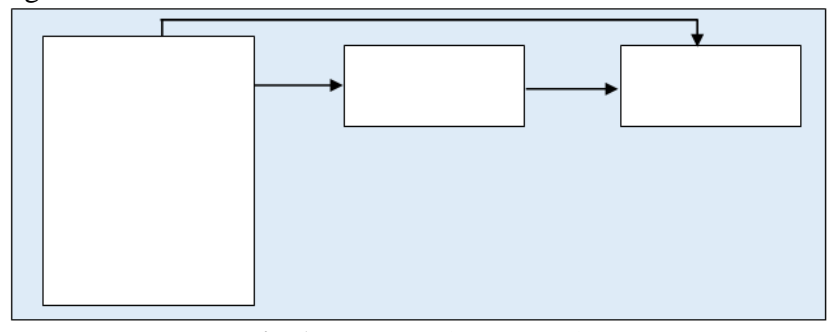

Fig. 1: Conceptual Framework

\section{Conclusion}

Building upon the Knowledge-Based View proposed by Grant (27), this study proposes to explore the role played by organizational creative climate on knowledge acquisition process of an organization in order to develop a more inclusive framework for R\&D project performance. This study also contributes to filling the gap in the previous literature by introducing the linkage between organizational creative climate, knowledge acquisition, and $R \& D$ project performance in the setting of medical devices industry. In other words, this study bridges the academic discipline by incorporating the government thrust that emphasizes on "re-engineering economic growth for greater prosperity" to encourage medical devices sector to shift towards more diverse and complex products through the increased R\&D capability.

\section{Acknowledgment}

This study is funded by the Fundamental Research Grant Scheme (203.PPAMC.6711544) supported by the Ministry of Higher Education Malaysia.

\section{References}

[1] OECD. OECD Reviews of innovation policy: Malaysia 2016. 2016.

[2] Cornell University, INSEAD, WIPO. The Global Innovation Index 2015: Effective innovation policies for development. Fontainebleau, Ithaca, and Geneva2005.

[3] Chao R, Kavidias S. A theoretical framework for managing the new product development portfolio: When and how to use to use strategic buckets. Management Science. 2008;54(5):907-21.

[4] Lee S, Lee H. Measuring and comparing the R\&D performance of government research institutes: A bottom-up data envelopment analysis approach. Journal of Informetrics. 2015;9:942-53.

[5] Gerwin D, Barowman NJ. An evaluation of research on integrated product development Management Science. 2002;48(7):938-53.

[6] Pinto JK, Slevin DP. Critical success factors in R\&D projects. Research-technology Management. 1989;32(1):31-5.

[7] Sahrom NS, Tan CL, Yahya S. Regulation, incentives and government policy: How does it stimulates R\&D engineers' innovative behavior in Malaysia biotechnology SMEs? Asian Academy of Management Journal. 2016;21(Supp. 1):49-73.

[8] Vera D, Crossan M. Strategic leadership and organizational learning. Academy Management Review. 2004;29(4):222-40.

[9] Van Woerkom M, Sanders K. The romance of learning from disagreement. The effect of cohesiveness and disagreement on knowledge sharing behavior and individual performance within teams. Journal of Business and Psychology. 2009;25:139-49.

[10] Chen G, Tjosvold D. Conflict management and team effectiveness in China: The mediating role of justice. Asia Pacific Journal of Management. 2002;19(4):557-72. 
[11] Mir FA, Pinnington AH. Exploring the value of project management: Linking project management performance and project success,. International Journal of Project Management. 2014;32(2):202-17.

[12] Joslin R, Müller R. Measuring and comparing the R\&D performance of government research institutes: A bottom-up data envelopment analysis approach. Journal of Informetrics. 2015;9(2015):942-53.

[13] Aizzat MN, Tan CL, Khor BH. The influence of organizational creative climate on product innovation: A study of Malaysian manufacturing firms. International Journal of Economics and Management. 2011;8(1):40-69.

[14] Ekvall G. Organizational climate for creativity and innovation European Journal of Work and Organizational Psychology. 1996;5:105-23.

[15] Litwin GH, Stringer RA. Motivation and organizational climate: Harvard Business School; 1968.

[16] Veldsman FHJ. Die Invloed van enkele Biografiese Veranderlikes opdie Werknemer se Persepsie van Organisasieklimaat en Organisasieverbondenheid. Unpublished Master's Thesis. University of Pretoria, Pretoria1995.

[17] Dickson MW, Hartog, Dem Hartog DN, Mitchelson K. Research on leadership in a cross-cultural context: Making progress, and raising new questions. The Leadership Quarterly,. 2003;14:729-68.

[18] Arabaci IB. Academic and administration personnel's perceptions of organizational climate. Procedia Social and Behavioral Sciences. 2010;2:4445-50.

[19] Jaw BS, Liu W. Promoting organizational learning and self-renewal in Taiwanese companies: The role of HRM. Human Resource Management. 2003;42(3):223-41.

[20] Amabile T. Growing up creative. New York: Crown; 1989.

[21] Isaksen SG. CPS: Linking creativity and problem solving. In: G Kaufmann TH, and K. H. Teigen, editor. Problem solving and cognitive processes Bergen-Sandviken, Norway: Fagbokforlaget Vigmostad \& Bjørke AS; 1995. p. 145-81.

[22] Hitt MA, Bierman L, Shimizu K, Kochhar R. Direct and moderating effects of human capital on strategy and performance in professional service firms: A resource-based perspective. Academy of Management Journal. 2001;44(1):13-28.

[23] Gooijer DJ. Designing a knowledge management performance framework. Journal of Knowledge Management. 2000;4(303-310).

[24] Silvianita A, Tan CL. A model linking knowledge managemen (KM) enabler, KM capability and operational performance in Indonesia automobile industry. Advanced Science Letters. 2017;23:640-3.

[25] Milton N. Filtering an organization's critical knowledge. Knowledge Management Review. 2007;10(1):28-33.

[26] Vouros GA. Technological issues towards knowledge-powered organizations. Journal of Knowledge Management. 2003;7(2):11427.

[27] Grant RM. Toward a knowledge-based theory of a firm. Strategic Management Journal. 1996;17((Winter special),):109-30.

[28] Darroch J. Knowledge management, innovation and firm performance

pp.101-115, . Journal of Knowledge Management. 2005;9(3):101-15.

[29] Carr JZ, Schmidt AM, Ford JK, DeShon RP. Climate perceptions matter: A meta-analytic patcarrh analysis relating molar climate, cognitive and affective states, and individual level work outcomes. Journal of Applied Psychology. 2003;88(4):605-19.

[30] Kunda G. Engineering culture: Control and commitment in a hightech corporation

Philadelphia, PA: Temple University Press; 1992.

[31] Tan CL, Aizzat MN. Human resource management practices and organizational innovation: assessing the mediating role of knowledge management effectiveness. Electronic Journal of Knowledge Management. 2011;9(2):155-67.

[32] Rashid Alshekaili SA. Human capital approach and innovation performance in Omani Industrial Firms: The role of knowledge managementl: Proceedings of the International (Spring) Conference on Asia Pacific Business Innovation \& Technology Management Bali, Indonesia; 2011. 